\title{
Contemporary Approach of Distal Extension Rehabilitation with Precision Attachment and Cast Partial Denture: A Report of Two Cases
}

\author{
Nitish K Varshney ${ }^{1}$, Tarun Gaur ${ }^{2}$, Sapna Rani ${ }^{3}$, Sakshi Gupta ${ }^{4}$
}

\begin{abstract}
Satisfactory restoration can be challenging in a patient with a partially edentulous situation especially when unilateral or bilateral posterior segment of teeth is missing. Successful restoration could be done with conventional and contemporary treatment options. Attachment retained cast partial dentures is one such treatment modality. Another treatment modality in such situations is implant supported prosthesis. Extracoronal precision attachment is preferred treatment option where implant therapy does not permit favorable outcome. This paper describes report of two cases in which rehabilitation of distal extension was done with precision attachments followed by cast partial denture.

Keywords: Cast partial denture, Extracoronal precision attachment, Partial edentulism, Retention.

International Journal of Prosthodontics and Restorative Dentistry (2019): 10.5005/jp-journals-10019-1247
\end{abstract}

\section{BACKGROUND}

Careful attention and meticulous treatment planning are required for an esthetically and functionally successful prosthetic rehabilitation. Available treatment options for the replacement of partially missing teeth includes fixed partial dentures, clasp retained removable partial dentures, removable partial dentures with precision attachments, implants and overdentures. Fixed restoration is definitely an apparently looking universal answer to most of the restoration replacements as they are neat, good looking and preferred by most of patients but their applications cannot be universal as because of limitations of cases with vertical loss of residual ridge structure and where extent of restoration needs to be long, we require some additional support. Cost and complexity of the prosthesis is an important point to be taken into consideration. ' Patient's concern and desire for esthetics, state of remaining teeth, and anatomical relationships of tissues must be taken into consideration. Implant supported prosthesis cannot be planned whenever there is insufficient amount of bone and economic reasons could be factor too. So, in such situation the preference should be an acrylic partial denture or a cast partial denture.

While replacing missing teeth, our primary goal should be to restore function and preservation of oral tissues and esthetics. Numerous removable partial dentures (RPDs) are made where negligence to above mentioned factors occurs while attention is paid in mere replacement of missing teeth. This results in detrimental effect on remaining natural dentition. Prosthodontic rehabilitation of distal extension in partially edentulous situations remains challenging. The support of distal extension RPD is derived from edentulous ridge and terminal abutment teeth. The terminal abutments act as fulcrum while functional movements of RPD as well as retentive clasps exert force on abutment teeth which may jeopardize the periodontium of abutment teeth. ${ }^{2}$

Cast partial dentures are retentive due to the presence of retainers and precision attachment components. An attachment could be defined as "A mechanical device for the fixation, retention
1,2Department of Prosthodontics, ITS Dental College, Ghaziabad, Uttar Pradesh, India

${ }^{3}$ Department of Prosthodontics, Sudha Rustagi College of Dental Sciences and Research, Faridabad, Haryana, India

${ }^{4}$ Noida, Uttar Pradesh, India

Corresponding Author: Tarun Gaur, Department of Prosthodontics, ITS Dental College, Ghaziabad, Uttar Pradesh, India, Phone: +91 6395292354, e-mail: tarungaur.10@gmail.com

How to cite this article:Varshney NK, GaurT, Rani S, et al. Contemporary Approach of Distal Extension Rehabilitation with Precision Attachment and Cast Partial Denture: A Report of Two Cases. Int J Prosthodont Restor Dent 2019;9(4):128-133.

Source of support: Nil

Conflict of interest: None

and stabilization of prosthesis." ${ }^{\prime 3}$ It's a connector which consists of two parts, one part is connected to a tooth, root or implant and the other part to prosthesis.

Mensor ${ }^{4}$ has classified attachments as extracoronal, intracoronal, bar type, push-button type and auxiliary type. They are also classified as rigid or solid, with or without a $U$ pin or screw and based on resiliency (vertical, hinge, rotatory type). ${ }^{4}$ Resilient types are highly recommended to avoid torque to the abutment tooth, in case of tooth tissue supported prosthesis. ${ }^{5}$ Selection criteria is based upon location, function, retention, space and economy. Depending on the location, extracoronal, intracoronal, radicular/ intraradicular stud type and bar type could be used. Intracoronal type, as described by Herman Chayes in 1906, consists of two parts, a flange (male) and a slot (female). ${ }^{6}$

Intracoronal attachment lies within the confines of the cusps and normal proximal axial contour or within the normal contours of the crown of a tooth.

Extracoronal is that attachment which exists external to, the crown portion of a natural tooth. The extracoronal attachment is projected outside the crown and provides either a rigid or resilient 
connection between the teeth and the prosthesis. Attachment retained cast partial dentures facilitate both functional and esthetic replacement of missing teeth. Studies have shown a survival rate of $83.35 \%$ up to 5 years, of $67.3 \%$ up to 15 years, and of $50 \%$ up to 20 years. ${ }^{6}$ This presented paper describes two bilateral distal extension Kennedy's class I cases, which are prosthetically restored using different types of extracoronal castable precision attachments.

\section{Case Descriptions}

\section{Case 1}

A 42-year-old female patient reported to the Department of Prosthodontics with the chief complaint of missing teeth in the lower jaw on both sides and wants replacement of lost dentition. On clinical examination, maxillary dentition was present and $34,35,36,37,45,46,47$ were missing in mandibular arch (Fig. 1). Treatment options available for the patient were implant prosthesis and cast partial denture. Patient was not ready for implants due to financial constraints. So, treatment plan decided was cast partial denture with precision attachment according to patients' desire. The periodontal status of remaining dentition was sound and can be utilized as an abutment for precision attachment. An informed and written consent was obtained from the patient prior to the treatment.

\section{Technique}

Diagnostic impressions were made and models were mounted on a semi adjustable articulator using a face bow. Then the diagnostic wax-up was done on the mounted casts. A putty matrix (Express STD Putty; 3M ESPE, St. Paul, Minn.) was then made over the completed diagnostic wax-up for evaluation of the existing space for the extracoronal resilient attachment. The attachment system was selected on the basis of space available (OT CAP, Rhein 83 Inc., USA). Tooth preparations of 32, 33, 43 and 44 abutment teeth were completed to receive porcelain fused to metal crowns (Fig. 2). Definitive impressions were made and poured in type IV gypsum product (Kalabhai). Wax-up was done for the prepared teeth and surveying, milling was done with the help of surveyor. The patrices were then added to the axial surfaces of the abutments lingual to the proximal contour during wax-up procedure (Fig. 3A). This ensures that the bulk of matrices do not interfere with the esthetics of buccal cusp of replacing denture tooth. Sprue attachment was

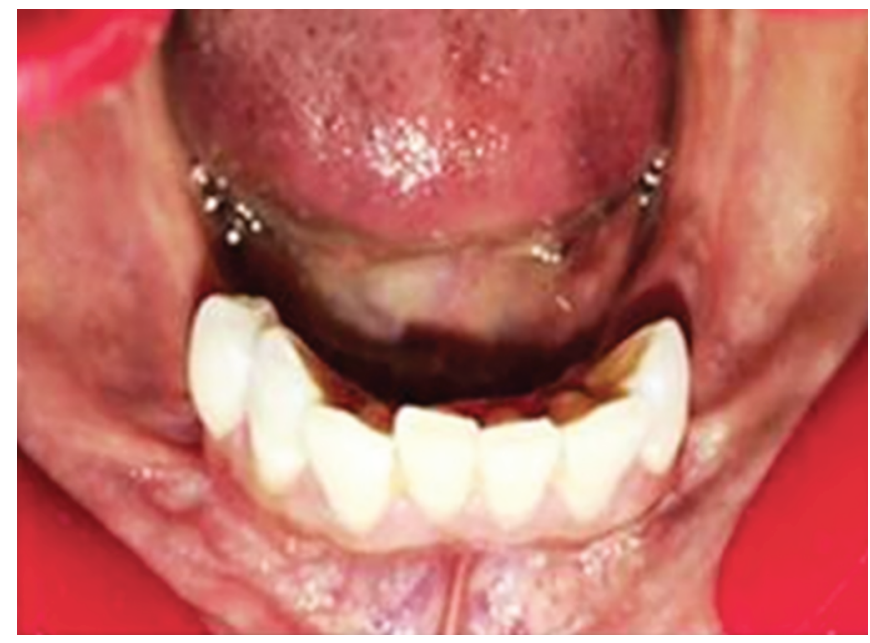

Fig. 1: Intraoral preoperative photograph showing Kennedy's class I done for casting procedure and finishing of the framework was done. To check the fit of the casting, metal try-in of the coping was done. Ceramic layering was done on the metal framework and bisque try-in was done. The fixed component including veneered metal ceramic crowns and the patrices were tried in the patient's mouth (Fig. 3B), then the matrices were placed on patrices in patient's mouth and a pickup impression was made with the help of polyvinyl siloxane impression material (Imprint II; 3M ESPE). Impression was poured in type III gypsum product (Kalabhai) and wax pattern was adapted on refractory cast for metal framework of cast partial denture (Fig. 4A). After fabrication of cast partial framework (Fig. 4B), wax rims were fabricated on denture base. Jaw relation was recorded and then mounted on articulator. Teeth arrangement was done and wax try-in was done in the patient's mouth. After wax try-in, acrylization of denture was performed (Fig. 5). Denture insertion was done after finishing and polishing of cast partial denture. After insertion, pick up of matrices was done in the denture in auto polymerizing resin (DPI, cold cure) (Fig. 6).

\section{Case 2}

Another 42-year-old female patient reported in the Department of Prosthodontics with chief complaint of maxillary bilateral posterior missing teeth (Kennedy's class I situation) (Fig. 7). Treatment options available were acrylic removable partial denture, implant supported fixed partial denture or cast removable partial denture. Precision attachment retained cast partial denture was selected for the patient for esthetic reasons. Maxillary right and left canine were prepared for porcelain fused to metal (PFM) crowns and attachment of precision attachment (Fig. 8). Castable attachment patterns (OT vertical, Rhein83) were attached on wax pattern of PFM crowns on working cast and casted (Fig. 9). After layering of crowns pickup impression was made on which wax pattern was adapted for cast partial denture which is then casted and finished (Fig. 10). Finished cast partial precision attachment retained denture was inserted into the patient's mouth (Fig. 11).

\section{Discussion}

Contemporary treatment in patients with distal extension ridges involves use of implants but in this patient removable dental prosthesis (RDP) in mandibular arch was an apt option because of anatomic, as well as economic factors. Retention in intact caries

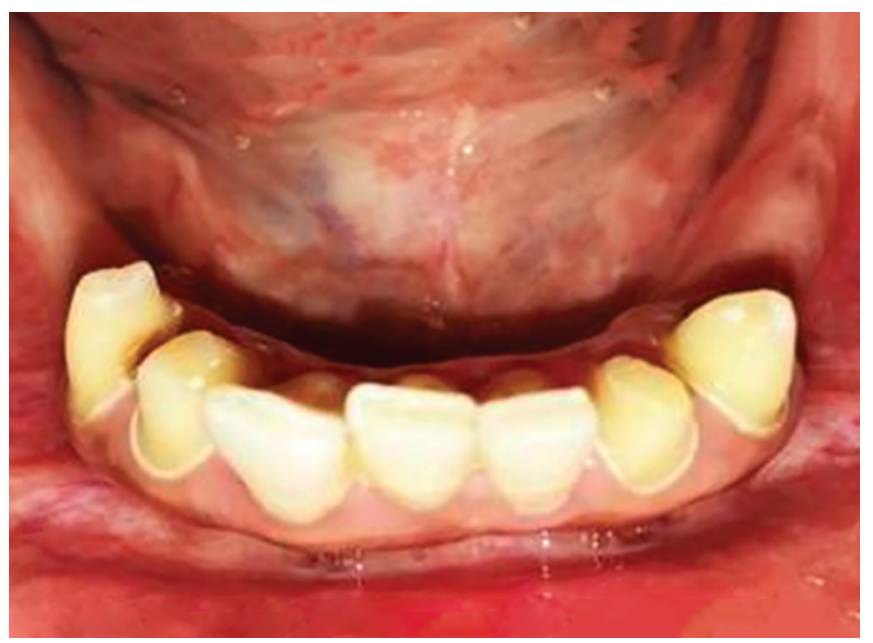

Fig. 2: Preparation of 32, 33, 43 and 44 abutment teeth 


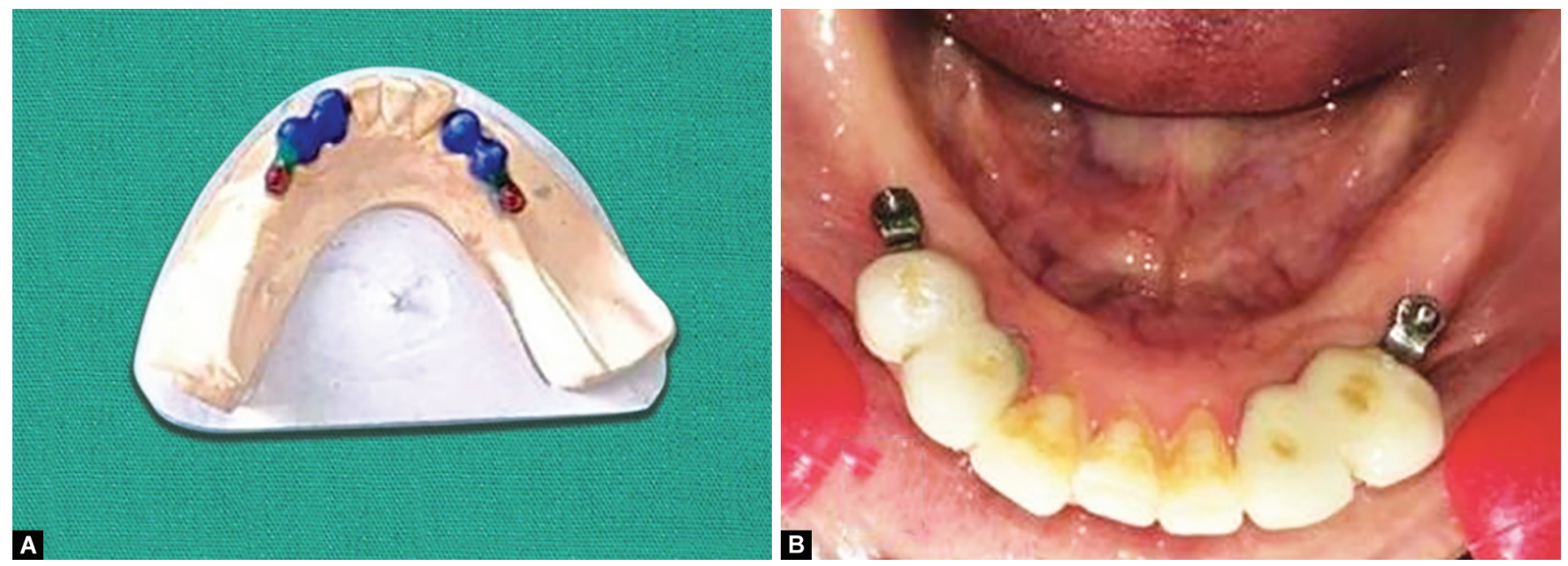

Figs $3 \mathrm{~A}$ and B: (A) Wax pattern adaptation on prepared teeth along with patrices; (B) Intraoral try-in of patrices
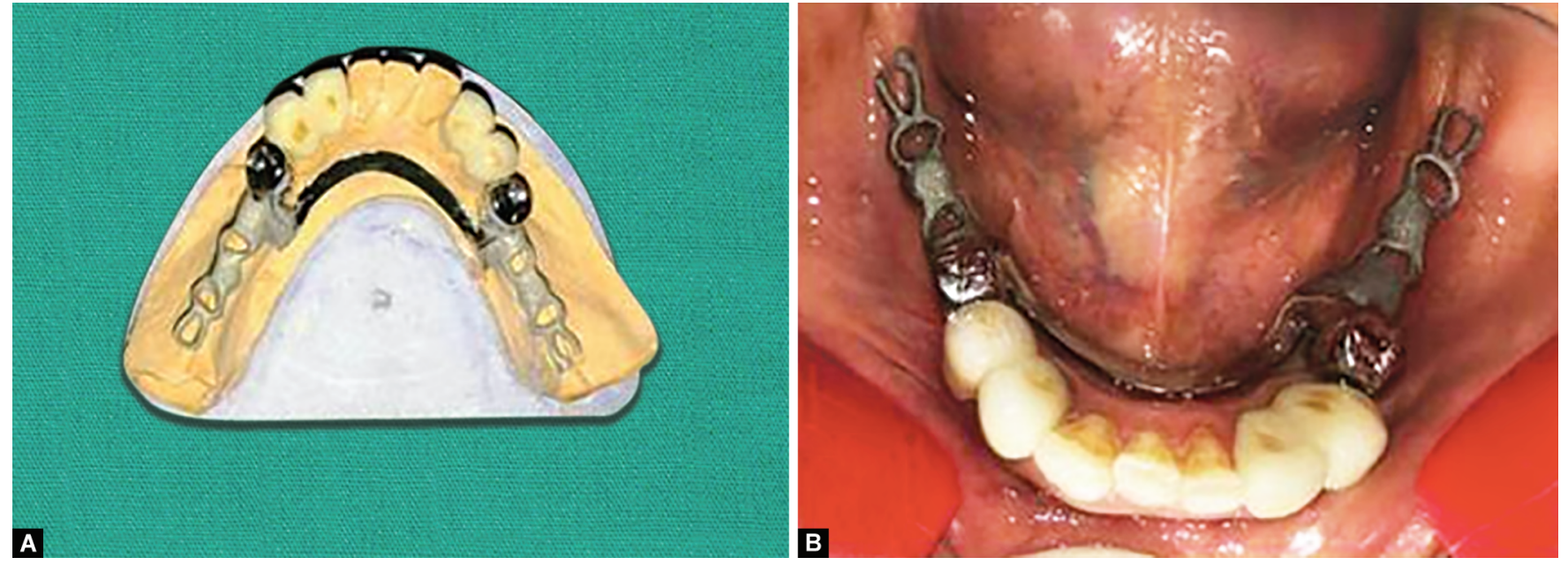

Figs 4A and B: (A) Adaptation of cast partial wax pattern; (B) Cast partial framework

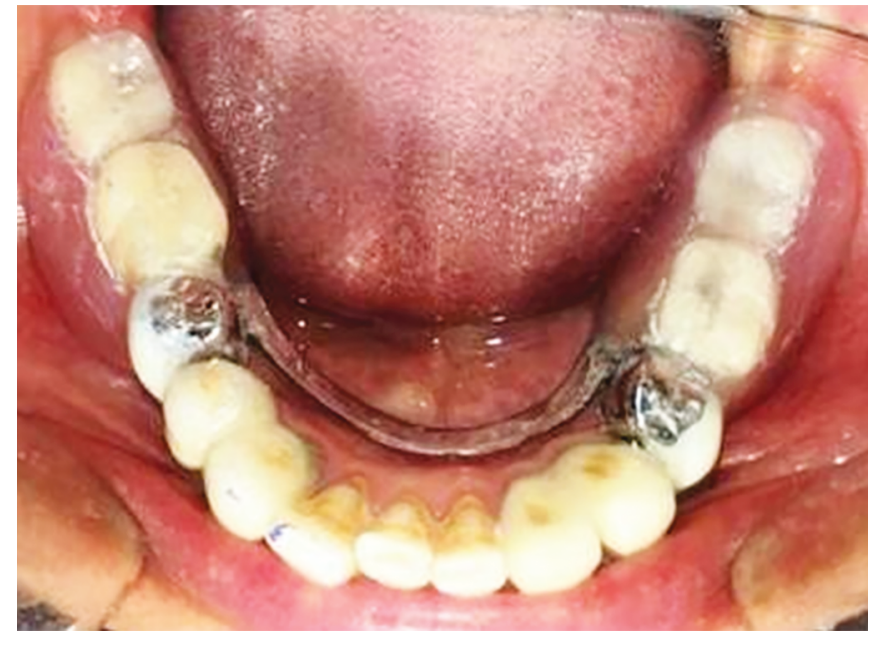

Fig. 5: Processed cast partial denture with precision attachment

free tooth to be used as retentive abutment is best provided with a clasp or adhesive attachments. However visible component of the clasp retained RDPs compromises esthetics. The main purpose of each precision attachment besides retention is its concealment within or under a restoration as an esthetically better alternative to a visible clasp retainer. ${ }^{1}$

Precision attachment is a connector consisting of two or more components. One part is connected to a tooth, root, or implant and the other part to the prosthesis providing a mechanical connection between the two. These attachments allow the prosthesis to combine the advantage of fixed and removable restoration. ${ }^{7}$ Precision attachment gives removable prosthesis the exceptional feature of improved esthetics, less postoperative adjustments, and improved comfort. It is mostly indicated for distal extension bases, long span edentulous arches, and nonparallel abutments. ${ }^{8}$

Most of the studies have shown that attachment retained cast partial dentures gives better function, comfort, esthetics, protect abutment teeth, less adjustments, easy to clean and can be worn most of the time by the patient. Its uses in fixed prostheses, overdentures and in implant therapy contribute to the success of prosthesis in terms of esthetics, comfort and function. ${ }^{9}$

Attachment retained cast partial prosthesis was fabricated for patient as primary advantage of attachment is esthetics as compared with clasp retained cast partial and also it was economical for the patient. Patient does not want surgical procedure for implant therapy. Attachments may also allow better cross arch stabilization and force transmission than clasps, but this is determined by the 

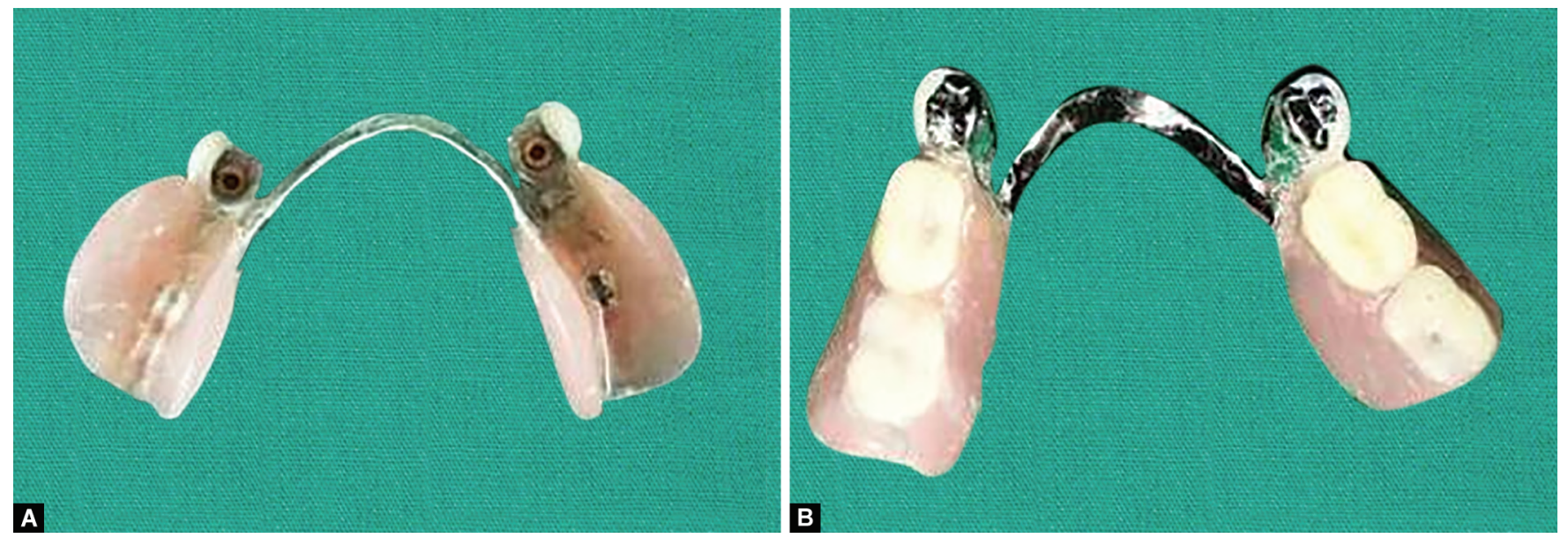

Figs 6 A and B: (A) Intaglio surface of cast partial denture; (B) Occlusal surface of cast partial denture
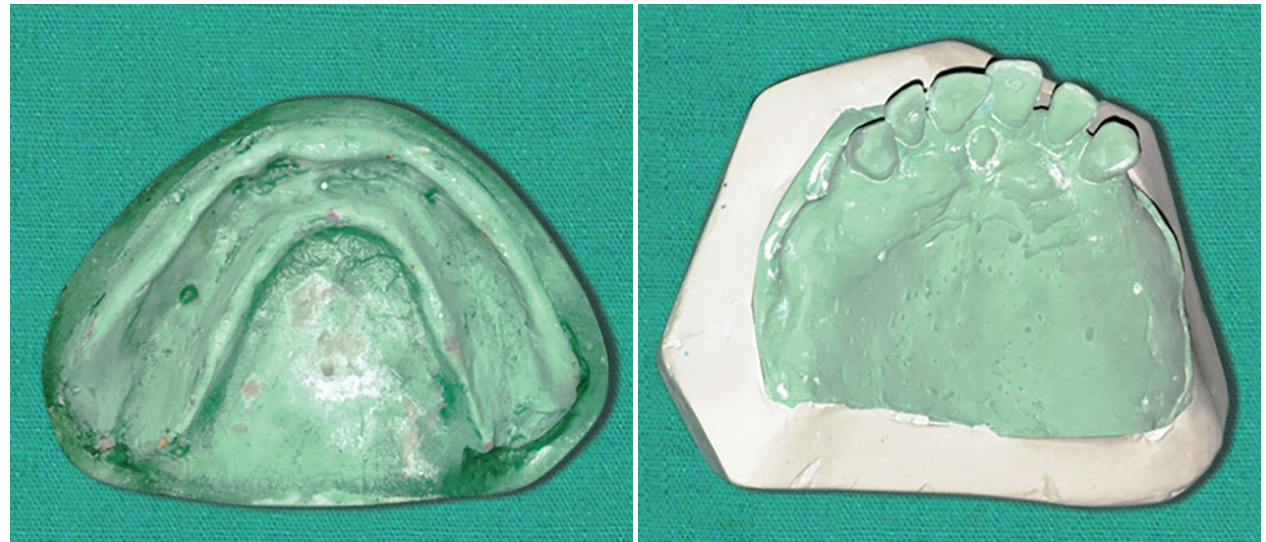

Fig. 7: Preoperative diagnostic casts of patients

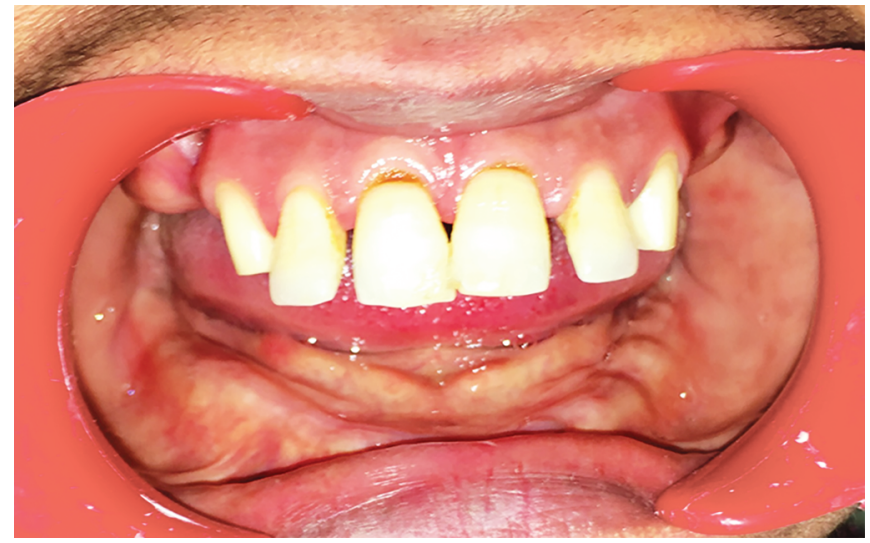

Fig. 8: Maxillary right and left canine prepared for porcelain fused to metal crowns

type of attachment used, the number of guiding surfaces, and the design and adaptation of the framework and the attachment. ${ }^{10}$

Intracoronal attachments require more vertical height to accommodate the attachment and require more tooth reduction weakening the tooth structure. ${ }^{11}$ That's why extracoronal attachments were used here. In case 1, 32, 33 and 43, 44 were splinted together for better distribution of forces. A similar case was presented by Patil, as it has been suggested that the most distal abutment splinted to the tooth anterior to the abutment significantly reduces the stress transmission to the supporting structures in these type of cases. ${ }^{1}$ Rhein83 OT cap attachment system was used on the distal of the crowns as an extension which allows a lot of vertical space for optimal esthetics because interocclusal distance was less. In case 2, Rhein 83 vertical attachment was used as more stability because more no of teeth was missing and interocclusal distance was also sufficient. The castable attachments can be easily shaped together with the crowns during wax-up stage avoiding adaptation procedures like welding of a metal attachment after crown casting.

Stress control on the abutments is an essential criterion for the success of distal extension cast partial denture which is achieved through dual impression technique, stable denture base, broad coverage, rigid design, splinting of abutments, physiologic shimming, proper selection of attachments. The recommended procedure has a number of advantages over the conventional prosthesis. In these presented case reports adequate crown height of abutments was there to receive the attachment; also, multiple abutments were splinted anterior to the edentulous span to facilitate better distribution of stresses. As the cast partial denture is removable type prosthesis, maintenance of the oral hygiene is much easier. Added to this the laboratory procedures are simple due to the available preformed prosthetic components and the treatment is much economical. Attachment retained partial dentures hence, provide long-term stability and more contentment to the patient as compared with clasp retained dentures. 

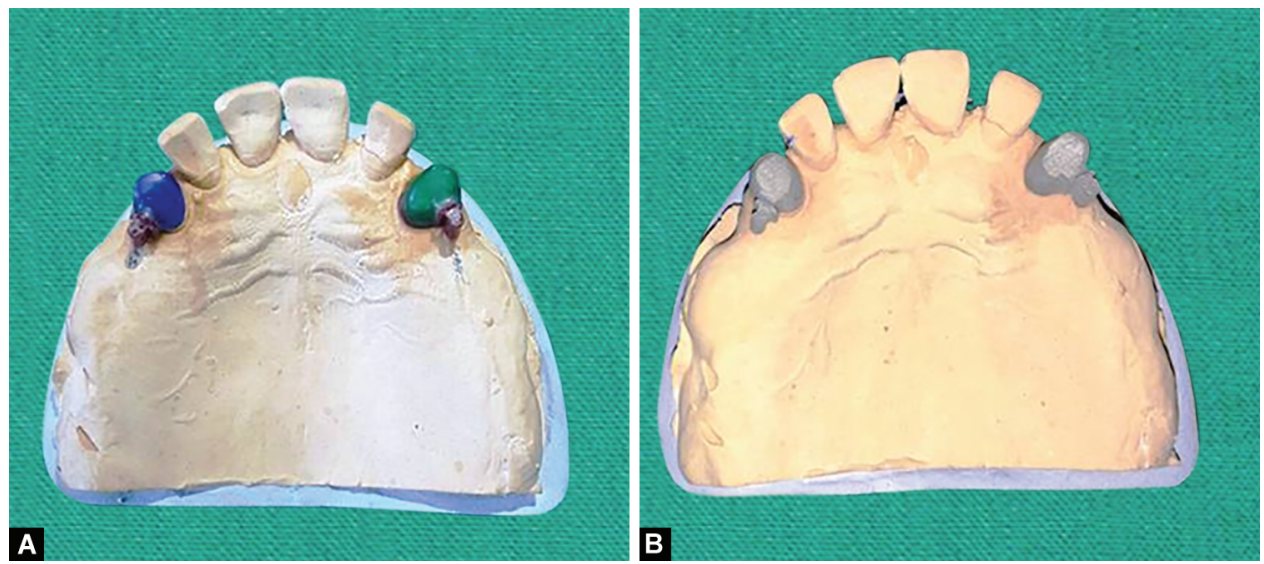

Figs 9A and B: (A) Wax pattern attachment for castable precision Rhein83 vertical attachment; (B) Casting of castable attachments
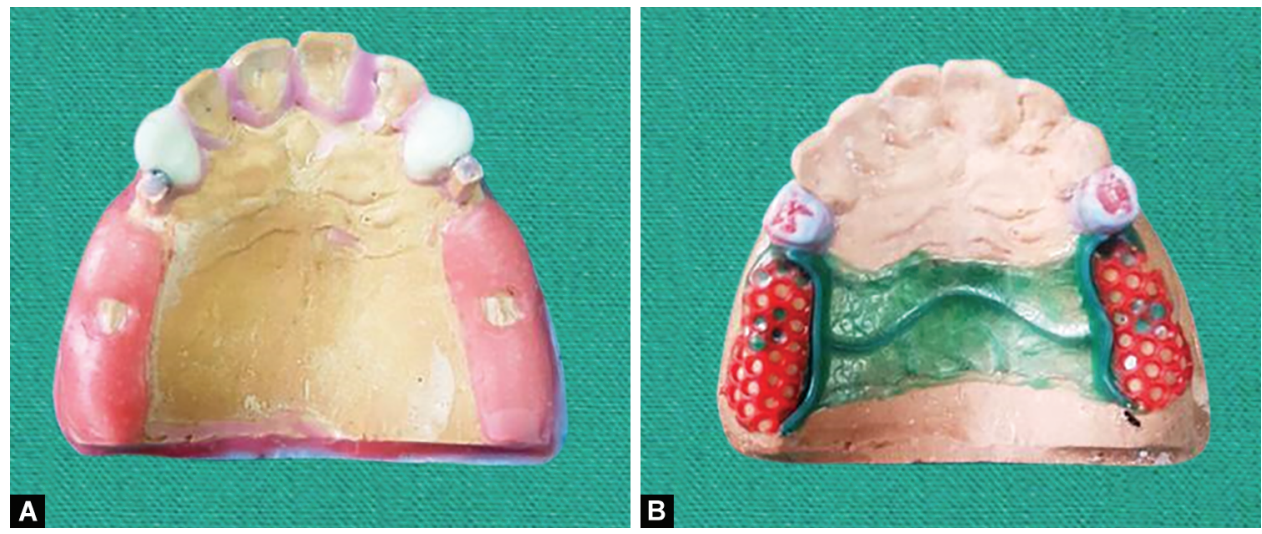

Figs 10A and B: (A) Precision attachments on cast with spacer; (B) Wax pattern adaptation on definitive cast
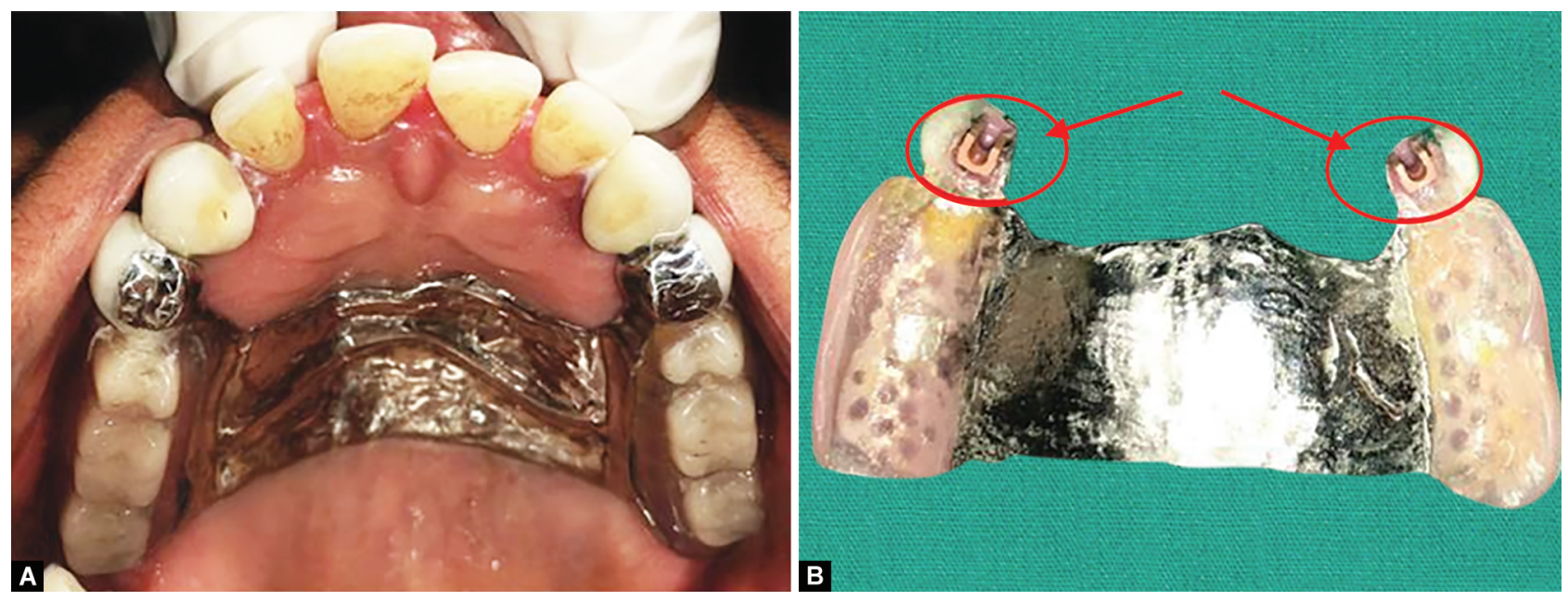

Figs 11 A and B: (A) Intraoral photograph of cast partial denture; (B) Intaglio surface of denture with female attachments

\section{ConcLusion}

A comprehensive evaluation, multi-disciplinary approach followed by a sequential treatment planning, worked out in harmony with the patient's esthetic demands, perceptions, and periodic recall preventative therapy is very important for a long-term successful outcome of removable precision attachment retained removable partial denture.

\section{References}

1. Patil R, Shetty O. Prosthetic rehabilitation using extra coronal attachments. Int J Dent Res 2019;4(1):05-08. DOI: 10.31254/ dentistry.2019.4102.

2. Gupta S, Rani S, Sikri A, et al. Attachment retained cast partial denture: conventional and contemporary treatment perspectives. Int J Oral Care Res 2016;4(4):312-316. DOI: 10.5005/jp-journals-10051-0071. 
3. The glossary of prosthodontic terms. J Prosthet Dent 2017;117(5S): e1-e105. DOI: 10.1016/j.prosdent.2016.12.001.

4. Mensor Jr MC. Classification and selection of attachments. J Prosthet Dent 1973;29(5):494-497. DOI: 10.1016/0022-3913(73)90026-7.

5. Thapa D, Shrestha P. Removable prosthesis with extra coronal attachment for the management of distal extension case: a case report. J Nepalese Prosthodont Soc 2018;1(2):101. DOI: 10.3126/ jnprossoc.v1i2.23869.

6. Makkar S, Chhabra A, Khare A. Attachment retained removable partial denture: a case report. Int J Clin Dent Sci 2011;2(2):39-43.

7. Preiskel HW. Precision Attachment in Prosthodontics, vol. 1-2, London, UK: Quintessence Publishing; 1995.
8. Feinberg E, Feinberg EM. Attachment retained partial partial denture. N Y State Dent J 1984;50(3):161-164.

9. Shakeel SK. Removable prosthesis using extra coronal precision attachment: a case report. Gulf Med J 2013;2(S1):S126-S129.

10. Schuyler $\mathrm{CH}$. An analysis of use and relative value of the precision attachment and the clasp in partial denture planning. J Prosthet Dent 1953;3(5):711-714. DOI: 10.1016/0022-3913(53) 90069-9.

11. Arya Nair R, Lal SJ, Anju D, et al. Prosthetic rehabilitation of partially edentulous maxilla with precision attachment. J IDA Attin Bra 2019;9(1):34. 